\title{
Relationship between size of varices and platelet count/spleen size ratio in cirrhotic patients
}

\author{
Kamil Ozdil, ${ }^{1}$ Oguzhan Ozturk, ${ }^{1}$ Ecem Sevim Calık, ${ }^{2}$ Eyup Sami Akbas, ${ }^{2}$ Evren Kanat, ${ }^{1}$ \\ Zuhal Calıskan, ${ }^{1}$ Hakan Demirdag, ${ }^{1}$ Resul Kahraman, ${ }^{1}$ Atilla Bulur, ${ }^{1}$ Nermin Mutlu Bilgic, ${ }^{1}$ \\ Levent Doganay, ${ }^{1}$ Hacı Mehmet Sokmen ${ }^{1}$ \\ ${ }^{1}$ Gastroenterology Clinic, Umraniye Training and Research Hospital, Istanbul, Turkey \\ ${ }^{2}$ Internal Medicine Clinic, Umraniye Training and Research Hospital, Istanbul, Turkey
}

\begin{abstract}
OBJECTIVE: This study investigated the relationship between size of gastroesophageal varices and platelet count/spleen diameter ratio in cirrhotic patients.
\end{abstract}

METHODS: The present study included 186 cirrhotic patients in whom gastroesophageal varices were seen during upper gastrointestinal system endoscopy. Clinical features, laboratory parameters, upper gastrointestinal system endoscopy, and abdominal ultrasonographic findings of patients were evaluated retrospectively. Platelet count/spleen diameter ratio $(\mathrm{P} / \mathrm{S})$ was calculated by dividing number of platelets in complete blood count $(\mathrm{CBC})$ to largest diameter of spleen. Varices were classified as small, medium, or large, and patients were separated into two groups for comparison: those with small varices and those with medium or large varices. Of the total, 66.7 $\%$ of the patients were men $(n=124)$ and $33.3 \%$ were women $(n=62)$. Esophageal varices were found in $82.7 \%$ and gastric varices were found in $17.3 \%$.

RESULTS: Patients with large esophageal varices were found to have significantly lower P/S compared to patients with small esophageal varices $(\mathrm{p}=0.04)$. In receiver operating characteristic $(\mathrm{ROC})$ curve analysis, $\mathrm{P} / \mathrm{S}$ and large varices correlated with $82 \%$ sensitivity and $79 \%$ positive predictive value. However, no statistically significant correlation between size of varices and $P / S$ was found in patients with gastric varices $(p=0.78)$.

CONCLUSION: In patients with esophageal varices, $\mathrm{P} / \mathrm{S}$ was found to be correlated with large varices with $82 \%$ sensitivity. However, this ratio did not predict large varices in patients with gastric varices. Prospective and randomized clinical researches are needed to clarify our findings.

Keywords: Cirrhosis; esophageal varices; gastric varices; platelet count; spleen diameter.

Received: January 02, 2016 Accepted: January 20, 2016 Online: June 07, 2016

Correspondence: Dr. Oguzhan OZTURK. Umraniye Egitim ve Arastirma Hastanesi, Gastroenteroloji Klinigi, Istanbul, Turkey.

Tel: +90216 6321818 e-mail: droguzozturk@hotmail.com

(c) Copyright 2016 by Istanbul Northern Anatolian Association of Public Hospitals - Available online at www.kuzeyklinikleri.com 
$\mathrm{P}$ ortal hypertension is a pathological condition that onsets with abnormal increase $(>5 \mathrm{~mm}$ hemoglobin $[\mathrm{Hg}])$ in hepatic venous pressure gradient and causes dilatation of portosystemic collaterals [1]. Portal hypertension manifests itself most frequently as a complication of hepatic cirrhosis, and subsequently leads to development of esophagogastric varices. The incidence of gastroesophageal varices in cirrhotic patients ranges between 50-66\% and life-threatening variceal bleeding can develop in $30-40 \%$ of patients with varices $[1,2]$. Therefore detection and treatment of varices at an early stage is vital. Incidence of variceal bleeding varies between $5-15 \%$. Most often it is esophageal varices that bleed; however, gastric varices are responsible for $10-36 \%$ of bleeding episodes. Studies have demonstrated that incidence of recurrent bleeding episodes and risk of mortality observed in cases with gastric variceal bleeding are higher when compared to esophageal varices [3-6].

The best method to detect varices in cirrhotic patients is endoscopic evaluation of upper gastrointestinal system, and if not contraindicated, it should be performed for every patient with diagnosis of cirrhosis [7]. However lack of necessary equipment for endoscopic screening, patient intolerance, and/or contraindication for endoscopy may delay detection of varices. In cases where endoscopy cannot be performed, various noninvasive methods have been developed to predict presence of varices. Therefore, correlation between various hematological parameters, imaging modalities, and endoscopic findings have been evaluated. Among these noninvasive methods, one of the most important is platelet count/spleen diameter ratio $(\mathrm{P} / \mathrm{S})$. It has been demonstrated in studies of cirrhotic patients that diagnostic sensitivity of $\mathrm{P} / \mathrm{S}$ for large varices approaches as much as $90 \%$ [8].

The present study investigated the relationship between size of varices and $\mathrm{P} / \mathrm{S}$ ratio.

\section{MATERIALS AND METHODS}

A total of 186 patients diagnosed with cirrhosis and gastroesophageal varices treated at Ümraniye Training and Research Hospital between 2009 and
2013 were included in the study. Patient data were evaluated retrospectively.

Diagnosis of cirrhosis was made using data obtained from clinical, laboratory examinations and/ or liver biopsy results. Cirrhotic patients who had undergone endoscopic examination at least once were included in the study. Laboratory tests were performed concomitantly with endoscopy, or 1 month before or after biopsy procedure. Only the most current endoscopic examination was taken into consideration for patients who had undergone multiple endoscopies. Demographic, clinical, and laboratory findings of patients were compared with endoscopic findings.

Disease stage of patients was determined according to the Child-Pugh scoring system based on prothrombin time (PT), albumin, bilirubin values, and presence of encephalopathy or ascites. Patients were classified into Child A (5-6 points), B (7-9 points), and $C$ (10-15 points) groups [9].

From automatically measured patient whole blood counts, the number of platelets in 1 cubic $\mathrm{mm}$ was determined. Platelet counts were divided by ultrasonographically measured maximum spleen diameter to calculate platelet counts/spleen diameter ratios $(\mathrm{P} / \mathrm{S})[10]$.

Endoscopically detected esophageal varices were classified as small (minimum elevation from the esophageal mucosa), moderate (tortuous varices occupying less than one-third of lumen), and large (tortuous varices occupying greater than one-third of lumen) [3]. Since treatment guidelines recommend primary prophylaxis for moderate and large varices, these two categories were combined to form a single group. Thus, varices were evaluated based on two groups: small and medium or large.

Evaluation of gastric varices according to their location was made according to the classification system proposed by Sarin et al. Gastric varices were classified as gastroesophageal varices (GOV), and isolated esophageal varices (IGV). GOV are subdivided into GOV1, GOV at the level of small curvature, and GOV2, GOV at the level of the greater curvature. IGV located in the fundus are classified as IGV1, and those located in other regions of the 
stomach are defined as IGV2 [11]. Gastric varices were also classified as small ( $<5 \mathrm{~mm})$, moderate (5$10 \mathrm{~mm}$ ), and large (>10 mm) [12].

Patients experiencing active variceal bleeding, those with a history of transjugular intrahepatic portosystemic shunt (TIPS) procedure, shunt surgery, and patients who had undergone band ligation, sclerotherapy, or variceal occlusion therapy were excluded from the study.

Approval for the study was obtained from the ethics committee of Ümraniye Training and Research Hospital.

\section{Statistical Analysis}

SPSS software (version 22.0; SPSS Inc., Chicago, IL, USA) was used for statistical analysis of the

TABLE 1. Comparison of patient characteristics according to variceal groups

\begin{tabular}{|c|c|c|c|c|c|c|c|}
\hline & $\begin{array}{c}\text { Patients with } \\
\text { esophageal } \\
\text { varices } \\
(n=154)\end{array}$ & $\begin{array}{c}\text { GOV1 } \\
(n=15)\end{array}$ & $\begin{array}{c}\text { GOV2 } \\
(n=13)\end{array}$ & $\begin{array}{c}\text { IGV1 } \\
(n=4) \\
(G O V 1+ \\
\text { GOV2+ } \\
\text { IGV1) } \\
(n=32)\end{array}$ & $\begin{array}{c}\text { Total all types } \\
\text { of gastric } \\
\text { varices }\end{array}$ & & \\
\hline & n (\%) & n (\%) & n (\%) & $\mathrm{n}(\%)$ & n (\%) & ${ }^{1} p$ & ${ }^{2} p$ \\
\hline \multicolumn{8}{|l|}{ Gender } \\
\hline Male & $97(63)$ & $13(86.6)$ & $11(84.6)$ & $3(75)$ & $27(84.4)$ & \multirow{2}{*}{${ }^{\mathrm{a}} 0.130$} & \multirow{2}{*}{${ }^{\mathrm{b}} 0.033^{*}$} \\
\hline Female & $57(37)$ & $2(13.4)$ & $2(15.4)$ & $1(25)$ & $5(15.6)$ & & \\
\hline \multicolumn{8}{|l|}{ Etiology } \\
\hline HBV & $47(30.5)$ & $3(20)$ & $4(30.8)$ & $3(75)$ & $10(31.2)$ & \multirow{7}{*}{${ }^{\mathrm{a}} 0.789$} & \multirow{7}{*}{${ }^{\mathrm{a}} 0.757$} \\
\hline $\mathrm{HCV}$ & $26(16.9)$ & $3(20)$ & $3(23.1)$ & $0(0)$ & $6(18.8)$ & & \\
\hline Ethanol & $11(7.1)$ & $1(6.6)$ & $3(23.1)$ & $0(0)$ & $4(12.5)$ & & \\
\hline Cryptogenic & 46 (29.9) & $6(40)$ & $2(15.3)$ & $1(25)$ & $9(28.1)$ & & \\
\hline NASH & $13(8.4)$ & $1(6.6)$ & $0(0)$ & $0(0)$ & $1(3.1)$ & & \\
\hline Autoimmune & $5(3.3)$ & $0(0)$ & $0(0)$ & $0(0)$ & $0(0)$ & & \\
\hline Other & $6(3.9)$ & $1(6.6)$ & $1(7.7)$ & $0(0)$ & $2(6.3)$ & & \\
\hline \multicolumn{8}{|l|}{$\mathrm{HCC}$} \\
\hline Absent & $125(81.2)$ & $13(86.6)$ & $10(76.9)$ & $2(50)$ & $25(78.1)$ & \multirow{2}{*}{${ }^{\mathrm{a}} 0.427$} & \multirow{2}{*}{${ }^{\mathrm{b}} 0.947$} \\
\hline Present & $29(18.8)$ & $2(13.4)$ & $3(23.1)$ & $2(50)$ & 7 (21.9) & & \\
\hline \multicolumn{8}{|l|}{ Child-Pugh } \\
\hline A & $45(29.2)$ & $8(53.3)$ & $8(61.5)$ & $1(25)$ & $17(53.1)$ & \multirow{3}{*}{${ }^{\mathrm{a}} 0.021^{*}$} & \multirow{3}{*}{${ }^{\mathrm{a}} 0.033^{*}$} \\
\hline B & $67(43.5)$ & $7(46.7)$ & $1(7.7)$ & $1(25)$ & $9(28.1)$ & & \\
\hline $\mathrm{C}$ & $42(27.3)$ & $0(0)$ & $4(30.8)$ & $2(50)$ & $6(18.8)$ & & \\
\hline \multicolumn{8}{|l|}{ Size of varices } \\
\hline Small & $42(27.3)$ & $4(26.7)$ & $6(46.2)$ & $3(75)$ & $13(40.6)$ & \multirow{3}{*}{${ }^{\mathrm{a}} 0.067$} & \multirow{3}{*}{${ }^{\mathrm{b}} 0.258$} \\
\hline Moderate & $67(43.5)$ & $10(66.7)$ & $3(23.1)$ & $0(0)$ & $13(40.6)$ & & \\
\hline Large & $45(29.2)$ & $1(6.7)$ & $4(30.8)$ & $1(25)$ & $6(18.8)$ & & \\
\hline
\end{tabular}

$1 p$ value obtained by separate evaluation of all variceal groups, $2 p$ value for comparison between patients with esophageal and gastric varices (GOV1 + GOV2 + IGV1); aChi-square test; bcontinuity correction; Child-Pugh classification: A: 5-6 pts B: 7-9 pts C: 10-15 pts.; *p<0.05.

GOV: Gastroesophageal varices; GOV1: Esophageal varices extending to cardia or lesser curve; GOV2: Esophageal and fundal varices; HBV: Hepatitis B virus; HCC: Hepatocellular carcinoma; HCV: Hepatitis C virus; IGV: Isolated gastric varices; IGV1: IGV located in the fundus; IGV2: IGV located elsewhere in stomach; NASH: Non-alcoholic steatohepatitis. 
data obtained from the study. Fitness of the parameters to normal distribution was evaluated using Shapiro-Wilk test. In addition to descriptive statistical methods (mean, standard deviation), in the comparison of quantitative data from more than two groups regarding parameters with nonnormal distribution, Kruskal-Wallis test was used. For intergroup comparisons of parameters with normal and nonnormal distribution, Student's-t test, and Mann-Whitney U test were used, respectively. Chisquare test and Yates' correction for continuity were also used to compare quantitative data. Optimal models were selected based on receiver operating characteristic (ROC) curve analysis. In the calculation of sensitivity and specificity, diagnostic screening tests were used. Level of statistical significance was accepted as $\mathrm{p}<0.05$.

\section{RESULTS}

The study was performed on 186 patients with a mean age of $59.51 \pm 12.75$ years (range 16-86 years). Study population consisted of 124 (66.7\%) male and 62 female (33.3\%) patients. Demographic characteristics of patients are provided in Table 1.

Patients had esophageal $(\mathrm{n}=154 ; 82.7 \%)$ and gastric varices $(n=32 ; 17.3 \%)$ Distribution of patients among subgroups of gastric varices were as follows: GOV1: $\mathrm{n}=15,46.8 \%$; GOV2: $\mathrm{n}=13$, $40.6 \%$; IGV1: $n=4,12.6 \%$. No instance of IGV2 was found. Female patients made up a greater percentage among those with esophageal varices $(37 \%)$ than all types of gastric varices $(15.6 \%)(p=0.033)$.

Patients were evaluated as four distinct groups (esophageal varices, GOV1, GOV2, and IGV1), and no significant difference between groups was found with respect to etiology of cirrhosis, hepatocellular carcinoma (HCC), or Child-Pugh classification $(p>0.05)$. Nor was a significant intergroup difference found for the same parameters when the patients were evaluated in two groups: those with esophageal varices or all types of gastric varices (GOV1 + GOV2 + IGV1) (Table 1).

TABLE2. Comparison between hematologic parameters and platelet count/spleen diameter ratios in variceal groups

\begin{tabular}{|c|c|c|c|c|c|c|c|}
\hline $\begin{array}{l}\text { Esophageal } \\
\text { varices } \\
(n: 154)\end{array}$ & $\begin{array}{l}\text { GOV1 } \\
(n: 15)\end{array}$ & $\begin{array}{l}\text { GOV2 } \\
(n: 13)\end{array}$ & $\begin{array}{l}\text { IGV1 } \\
(n: 4)\end{array}$ & $\begin{array}{l}\text { Total gastric varices } \\
\qquad(\mathrm{n}: 32)\end{array}$ & 1ap & 2bP & \\
\hline Age & $59.19 \pm 13.44$ & $59.53 \pm 8.69$ & $61 \pm 9.59$ & $66.75 \pm 3.86$ & $61.03 \pm 8.74$ & ${ }^{\mathrm{a}} 0.492$ & ${ }^{\mathrm{b}} 0.334$ \\
\hline $\mathrm{T} / \mathrm{D}$ & $788.81 \pm 462.73$ & $601.29 \pm 307.21$ & $838.79 \pm 707.97$ & $869.73 \pm 761.48$ & $723.13 \pm 539.54$ & ${ }^{\mathrm{a}} 0.513$ & ${ }^{c} 0.216$ \\
\hline $\begin{array}{l}\text { Platelets } \\
\left(\mathrm{K} / \mathrm{mm}^{3}\right)\end{array}$ & $117195.39 \pm 64326.69$ & $94273.33 \pm 43149.15$ & $117366.67 \pm 80383.03$ & $122750 \pm 85425.89$ & $106887.1 \pm 62224.96$ & ${ }^{\mathrm{a}} 0.557$ & ${ }^{c} 0.222$ \\
\hline $\begin{array}{l}\text { Leukocyte } \\
\left(\mathrm{K} / \mathrm{mm}^{3}\right)\end{array}$ & $6218.62 \pm 3607.01$ & $4386 \pm 1618.55$ & $5688.33 \pm 2467.62$ & $7780 \pm 3022.63$ & $5328.06 \pm 2380.36$ & ${ }^{\mathrm{a}} 0.113$ & ${ }^{c} 0.292$ \\
\hline $\begin{array}{l}\text { Erythrocyte } \\
\text { (million/ } / \mathrm{L} \text { ) }\end{array}$ & $3.75 \pm 0.82$ & $3.77 \pm 0.5$ & $3.92 \pm 1$ & $3.94 \pm 1.26$ & $3.85 \pm 0.80$ & ${ }^{\mathrm{a}} 0.847$ & ${ }^{\mathrm{b}} 0.526$ \\
\hline $\begin{array}{l}\text { Hemoglobin } \\
(\mathrm{gr} / \mathrm{dl})\end{array}$ & $11.14 \pm 2.44$ & $11.07 \pm 2.16$ & $10.64 \pm 2.65$ & $11.88 \pm 3.5$ & $11.00 \pm 2.48$ & ${ }^{\mathrm{a}} 0.834$ & b 0.785 \\
\hline Mpv & $9.39 \pm 1.62$ & $8.6 \pm 1.27$ & $9.22 \pm 1.11$ & $9.38 \pm 1.28$ & $8.94 \pm 1.22$ & ${ }^{\mathrm{a}} 0.332$ & ${ }^{\mathrm{b}} 0.147$ \\
\hline
\end{tabular}

${ }^{*} \mathrm{p}<0.05$

${ }^{1} p$ value obtained by separate evaluation of all variceal groups, ${ }^{2} p$ value for comparison between esophageal and total gastric varices (esophageal varices, GOV1 + GOV2 + IGV1); a: Kruskal- Wallis test b: Student's t-test; c: Mann-Whitney U test.

GOV: Gastroesophageal varices; GOV1: Esophageal varices extending to cardia or lesser curve; GOV2: Esophageal and fundal varices; IGV: Isolated gastric varices; IGV1: IGV located in the fundus; IGV2: IGV located elsewhere in stomach; Mpv: Mean platelet volume; Plt: platelet; WBC: white blood cell count. 


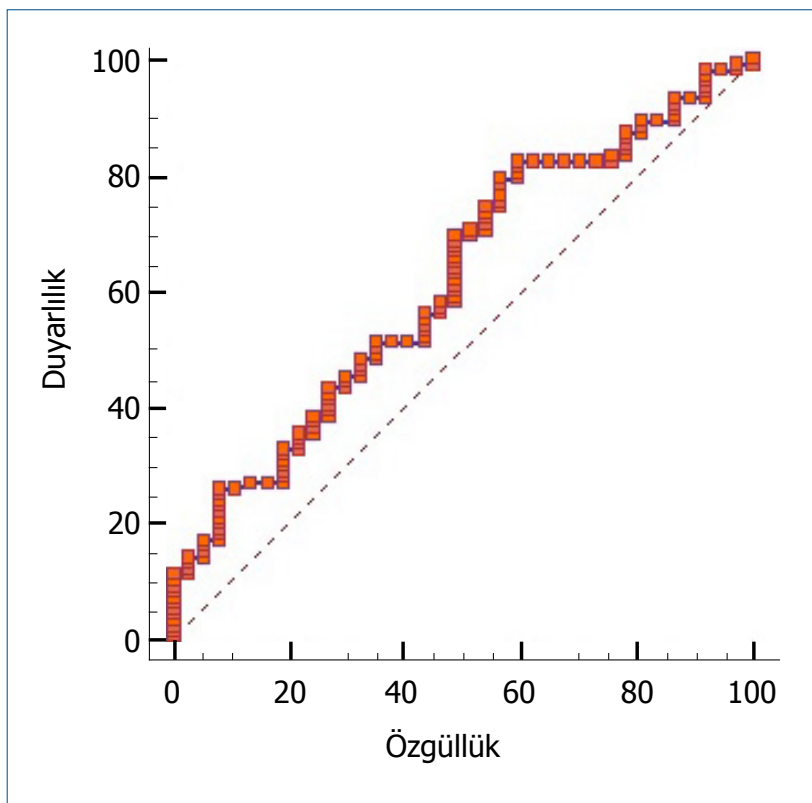

FIGURE 1. Correlation between platelet count/spleen diameter ratio and size of varices.

Comparison of groups of varices based on $\mathrm{P} / \mathrm{S}$ did not yield a significant difference; therefore, a significant correlation was not found between $\mathrm{P} / \mathrm{S}$ and location of varices (Table 2).

Correlation between size of varices and $\mathrm{P} / \mathrm{S}$ was investigated. Mean P/S ratios were 742.16 \pm 450.59 in large (medium-large) varices, and $917.41 \pm 477.51$ in small varices. Mean $\mathrm{P} / \mathrm{S}$ ratio was significantly lower in large varices group $(p=0.04$, Table 3$)$. ROC curve analysis determined P/S limit of 1057. $\mathrm{P} / \mathrm{S}$ ratios below this value had $82 \%$ sensitivity, $40 \%$ specificity, $79 \%$ positive, and $45 \%$ negative predictive values (Figure 1). P/S ratio was not signifcantly different between large and small gastric varices $(p>0.05)$.

Esophageal varices were compared to all types of gastric varices with regard to stage of cirrhosis (based on Child-Pugh classification), and significant intergroup difference was detected $(p=0.033)$. Patients with Child-Pugh Stage A cirrhosis were significantly more numerous $(53.1 \%)$ in all cases with gastric varices relative to the group with esophageal varices $(29.2 \%)(p=0.016)$. However, among Child B and Child C patient groups, the number of patients with esophageal varices did not differ significantly from those with gastric varices $(p>0.05)$.

\section{DISCUSSION}

One of the most important complications of cirrhosis is variceal bleeding. Guidelines published by the Baveno VI Consensus Workshop and The American Association for the Study of Liver Dis-

TABLE 3. Comparison of grade of esophageal varices, platelet count/spleen diameter ratio and hematological parameters

\begin{tabular}{|c|c|c|c|}
\hline & $\begin{array}{l}\text { Patients with small varices } \\
\qquad(n=42)\end{array}$ & $\begin{array}{l}\text { Patients with large varices } \\
\qquad(\mathrm{n}=112)\end{array}$ & \\
\hline PIt/spleen & $917.41 \pm 477.51$ & $742.16 \pm 450.59$ & $0.040^{*}$ \\
\hline \multicolumn{4}{|l|}{ Plt } \\
\hline$\left(\mathrm{K} / \mathrm{mm}^{3}\right)$ & $130119.05 \pm 72581.34$ & $112260.91 \pm 60513.32$ & 0.181 \\
\hline \multicolumn{4}{|l|}{ WBC } \\
\hline$\left(\mathrm{K} / \mathrm{mm}^{3}\right)$ & $6090 \pm 3579.83$ & $6267.73 \pm 3632.43$ & 0.974 \\
\hline \multicolumn{4}{|l|}{ RBC } \\
\hline$\left(10^{6} / \mu \mathrm{L}\right)$ & $3.87 \pm 0.88$ & $3.7 \pm 0.8$ & 0.205 \\
\hline $\mathrm{Hgb}(\mathrm{gr} / \mathrm{dL})$ & $11.75 \pm 2.4$ & $10.9 \pm 2.42$ & 0.060 \\
\hline Mpv & $8.96 \pm 1.26$ & $.56 \pm 1.71$ & 0.125 \\
\hline
\end{tabular}


ease (AASLD) recommend screening for the presence of varices in all cirrhotic patients using upper gastrointestinal system endoscopy, and application of prophylaxis is advised in patients with a risk of bleeding $[3,13]$. However, in cases where endoscopic procedures could not be performed or were postponed because of difficulties inherent to endoscopic examination (i.e., experienced team and cost), and various patient-related factors (i.e., state of health, fear of procedure), diagnosis and treatment may be delayed. Therefore, noninvasive methods have been developed to predict the presence and size of varices. In a study by Gue et al,, correlation between size of varices and lower platelet and leukocyte counts was demonstrated [14]. Similarly, studies conducted in cirrhotic patients have demonstrated that decrease in platelet count and supranormal diameter of spleen are independent risk factors in determination of large esophageal varices $[15,16]$.

In recent years, $\mathrm{P} / \mathrm{S}$ has been added to these noninvasive parameters. In studies of Mexican cirrhotic patients, González-Ojeda et al. demonstrated that $\mathrm{P} / \mathrm{S}$ could predict presence of varices with $84 \%$ sensitivity and 70\% specificity [17]. Sarangapani et al. reported that platelet count/spleen diameter ratio could predict large esophageal varices with higher sensitivity and specificity [18]. Meta-analysis performed by Ying et al. consisting of 20 studies and a total of 3063 patients evaluated the performance of platelet count/spleen diameter ratio in the prediction of esophageal varices, and the authors demonstrated that the noninvasive method can predict esophageal varices with $92 \%$ sensitivity [19].

In the present study, $\mathrm{P} / \mathrm{S}$ predicted size of the varices with $82 \%$ sensitivity and $79 \%$ positive predictive value. According to this outcome, in the follow-up of cirrhotic patients with varices who cannot tolerate and/or do not consent to endoscopic examination, $\mathrm{P} / \mathrm{S}$ ratio can be a useful noninvasive method to evaluate size of varices.

In various studies, Child-Pugh scores have been demonstrated to be an important prognostic criterion in the prediction of survival of cirrhotic patients as well as bleeding risk of preexisting varices $[9,20,21]$. Similarly, some studies have demonstrated close association between Child-Pugh scores and recurrent bleeding risk of variceal bleeds that ceased spontaneously or as a result of treatment $[22,23]$. Distribution of patients according to groups based on Child-Pugh stages revealed that cirrhotic patients in Child A stage were more numerous in all groups with gastric varices. For patients with gastric varices, diagnosis at Child $\mathrm{A}$ stage can contribute favorably to prognosis, improve hemostatic control, and decrease recurrence rates. This outcome may be important for patients with gastric varices in Turkish population. Large-scale prospective studies to support our findings are needed.

Retrospective design of the present study is a limitation. Prospective studies should be conducted for better evaluation and follow-up of patients with varices. Limited number of patients and conducting the study in a certain region of Turkey are further limitations that may not reflect the present condition throughout the country. Multi-centered studies will yield more reliable data.

In conclusion, this study demonstrated that $\mathrm{P} / \mathrm{S}$ ratio could predict presence of large varices with a high sensitivity in patients with esophageal varices. Therefore, in the follow-up of varices in cirrhotic patients with esophageal varices not amenable to endoscopy, $\mathrm{P} / \mathrm{S}$ ratio can be used as a noninvasive parameter. Child A stage cirrhosis was more frequently detected in patients with gastric varices, which may be important for prognosis. Large-scale prospective studies are needed.

Conflict of Interest: No conflict of interest was declared by the authors.

Financial Disclosure: The authors declared that this study has received no financial support.

Authorship contributions: Concept - K.Ö., O.Ö.; Design K.Ö., O.Ö.; Materials - K.Ö., O.Ö.; Data collection and/or processing - E.S.Ç, E.S.A, E.K., H.D., Z.Ç., R.K.; Analysis and/or interpretation - K.Ö.; Literature search - Writing - O.Ö., R.K. Critical review - 0.0̈.

\section{REFERENCES}

1. Miyaaki $H$, Ichikawa T, Taura N, Miuma S, Isomoto $H$, Nakao $\mathrm{K}$. Endoscopic management of esophagogastric varices in Japan. Ann Transl Med 2014;2:42.

2. Moodley J, Lopez R, Carey W. Compliance with practice guidelines and risk of a first esophageal variceal hemorrhage in pa- 
tients with cirrhosis. Clin Gastroenterol Hepatol 2010;8:703-8.

3. Garcia-Tsao G, Sanyal AJ, Grace ND, Carey W. Practice Guidelines Committee of the American Association for the Study of Liver Diseases, Practice Parameters Committee of the American College of Gastroenterology. Prevention and management of gastroesophageal varices and varicealhemorrhage in cirrhosis. Hepatology 2007;46:922-38. Crossref

4. Qureshi W, Adler DG, Davila R, Egan J, Hirota W, Leighton J, et al. ASGE Guideline: the role of endoscopy in the management of variceal hemorrhage, updated July 2005. Gastrointest Endosc 2005;62:651-5. Crossref

5. de Franchis R. Revising consensus in portal hypertension: report of the Baveno $\mathrm{V}$ consensus workshop on methodology of diagnosis and therapy in portal hypertension.J Hepatol 2010;53:762-8.

6. Sarin SK, Kumar A. Endoscopic Treatment of Gastric Varices. Clin Liver Dis. 2014;18:809-27. Crossref

7. de Franchis R. Updating consensus in portal hypertension: Report of the Baveno III consensus workshop on definitions, methodology and therapeutic strategies in portal hypertension. J Hepatol 2000;33:846-52. Crossref

8. Giannini EG, Zaman A, Kreil A, Floreani A, Dulbecco P, Testa $\mathrm{E}$, et al. Platelet count/spleen diameter ratio for the noninvasive diagnosis of esophageal varices: results of a multicenter, prospective, validation study. Am J Gastroenterol 2006;101:2511-9.

9. Child CG, Turcotte JG. Surgery and portal hypertension. In: Child CG, editor. The liver and portal hypertension. Philadelphia: Saunders; 1964. p. 50-64.

10. Lamb PM, Lund A, Kanagasabay RR, Martin A, Webb JA, Reznek RH. Spleen size: how well do linear ultrasound measurements correlate with three-dimensional CT volume assessments? Br J Radiol 2002;75:573-7. Crossref

11. Sarin SK, Lahoti D, Saxena SP, Murthy NS, Makwana UK. Prevalence, classification and natural history of gastric varices: a longterm follow-up study in 568 portal hypertension patients. Hepatology 1992;16:1343-49. Crossref

12. Triantafyllou M, Stanley AJ. Update on gastric varices. World J Gastrointest Endosc 2014;6:168-75. Crossref

13. de Franchis R; Baveno VI Faculty. Expanding consensus in por- tal hypertension: Report of the Baveno VI Consensus Workshop: Stratifying risk and individualizing care for portal hypertension. J Hepatol 2015;63:743-52. Crossref

14. Gue CS, Yap CK, Ng HS. The correlation between cytopenia and esophageal varices in patients with liver cirrhosis. Med J Malaysia 2004;59:604-8.

15. Madhotra R, Mulcahy HE, Willner I, Reuben A. Prediction of esophageal varices in patients with cirrhosis. J Clin Gastroenterol 2002;34:81-5. Crossref

16. Sharma SK, Aggarwal R. Prediction of large esophageal varices in patients withcirrhosis of the liver using clinical, laboratory and imaging parameters. J Gastroenterol Hepatol 2007;22:1909-15.

17. González-Ojeda A, Cervantes-Guevara G, Chávez-Sánchez M, Dávalos-Cobián C, Ornelas-Cázares S, Macías-Amezcua MD, et al. Platelet count/spleen diameter ratio to predict esophageal varices in Mexican patients with hepatic cirrhosis. World J Gastroenterol 2014;20:2079-84. Crossref

18. Sarangapani A, Shanmugam C, Kalyanasundaram M, Rangachari B, Thangavelu P,Subbarayan JK. Noninvasive prediction of large esophageal varices in chronic liver disease patients. Saudi J Gastroenterol 2010;16:38-42. Crossref

19. Ying L, Lin X, Xie ZL, Hu YP, Shi KQ. Performance of platelet count/spleen diameter ratio for diagnosis of esophageal varices in cirrhosis: a meta-analysis. Dig Dis Sci 2012;57:1672-81.

20. North Italian Endoscopic Club for the Study and Treatment of Esophageal Varices. Prediction of the first variceal hemorrhage in patients with cirrhosis of the liver and esophageal varices. A prospective multicenter study. N Engl J Med 1988;319:983-9.

21. Park EJ, Jang JY, Lee JE, Jeong SW, Lee SH, Kim SG, et al. The risk factors for bleeding of fundal varices in patients with liver cirrhosis. Gut Liver 2013;7:704-11. Crossref

22. Jun CH, Kim KR, Yoon JH, Koh HR, Choi WS, Cho KM, et al. Clinical outcomes of gastric variceal obliteration using N-butyl2 -cyanoacrylate in patients with acute gastric variceal hemorrhage. Korean J Intern Med 2014;29:437-44. Crossref

23. Jensen DM. Endoscopic screening for varices in cirrhosis: findings, implications, and outcomes. Gastroenterology 2002;122:1620-30. Crossref 